\title{
Correction to: Sustainable bioethanol and value-added chemicals production from paddy residues at pilot scale
}

\author{
Tan M. Le ${ }^{1,5} \cdot$ Uyen P. N. Tran ${ }^{2} \cdot$ Yen H. P. Duong ${ }^{1,5} \cdot$ Quan D. Nguyen $^{3,4,5} \cdot$ Viet T. Tran $^{1,4,5} \cdot$ Phong T. Mai $^{4,5}$ (D) \\ Phung K. Le $e^{1,4,5}$
}

Published online: 24 May 2021

○) Springer-Verlag GmbH Germany, part of Springer Nature 2021

\section{Correction to: Clean Technologies and Environmental Policy https://doi.org/10.1007/s10098-021-02097-w}

In the original publication, the affiliation of all the authors was processed incorrectly. It has been updated in this correction.

The original article has been corrected.

Publisher's Note Springer Nature remains neutral with regard to jurisdictional claims in published maps and institutional affiliations.

The original article can be found online at https://doi.org/10.1007/ s10098-021-02097-w.

Viet T. Tran

trantanviet@hcmut.edu.vn

$\triangle$ Phung K. Le

phungle@hcmut.edu.vn

1 Refinery and Petrochemicals Technology Research Center (RPTC), Ho Chi Minh City University of Technology (HCMUT), 268 Ly Thuong Kiet Street, Ho Chi Minh City, Vietnam

2 Institute of Biotechnology, Van Hien University, Ho Chi Minh City, Vietnam

3 Laboratory of Biofuel and Biomass Research, Ho Chi Minh City University of Technology (HCMUT), 268 Ly Thuong Kiet Street, Ho Chi Minh City, Vietnam

4 Faculty of Chemical Engineering, Ho Chi Minh City University of Technology (HCMUT), 268 Ly Thuong Kiet Street, Ho Chi Minh City, Vietnam

5 Vietnam National University Ho Chi Minh City (VNU-HCM), Linh Trung Ward, Thu Duc District, Ho Chi Minh City, Vietnam 